\title{
VIBRATION ACTUATOR SYSTEM FOR INTERNAL INSPECTION OF LARGE COMPLEX IRON STRUCTURES
}

\author{
* Hiroyuki Yaguchil and Yusuke Itoh ${ }^{1}$ \\ ${ }^{1}$ Faculty of Engineering, Tohoku Gakuin University, Japan \\ * Corresponding Author, Received: 06 Oct. 2021, Revised: 01 Dec. 2021, Accepted: 09 Jan. 2022
}

\begin{abstract}
In recent years, many large structures have been constructed all over the world due to economic development. Especially in Japan, more than 50 years have passed since the intensive construction of large structures during the period of high growth known as the Japanese economic miracle. As these structures age, they need to be inspected, and numerous robots have been proposed for structural inspection. However, the technology for inspection of large structures by robots remains immature. This paper proposes a vibration actuator system that can move a robot over an iron structure having a complicated surface, such as a stepped surface. A prototype vibration actuator system was built, in which four vibration actuators and wheels containing magnets were combined with flexible silicone rubber "backbone." Actual climbing tests showed that this actuator system can move smoothly over vertical steps. Further, this system can be equipped with an automatic tapping device, which might allow it to inspect the main towers of a large bridge.
\end{abstract}

\section{Keywords: Vibration, Actuator system, Inspection, Magnetic wheel, Complex iron structure.}

\section{INTRODUCTION}

In recent years, many large structures have been constructed in every country due to economic development. Especially in Japan, more than 50 years have passed since the intensive construction of large structures during the period of high growth known as the Japanese economic miracle. Therefore, the maintenance requirements for these structures have increased since 2010. Within 20 years, it is expected that more than $50 \%$ of Japan's social infrastructure will be more than 50 years old Old infrastructure was built without seismic standards, so there is a risk of collapse in the event of a major disaster. For this reason, inspection and maintenance of social infrastructures, such as large bridges and storage tanks, is extremely important. In particular, there is a high demand for inspection at the cable joint of a cable-stayed bridge having a height of the main tower over $200 \mathrm{~m}$.

Numerous robots have been proposed for structural inspection. Adhesion methods for wall surface movement include the following proposed techniques: mimicking of a living leech [1], roller structure with a belt and suction cups [2], van der Waals forces [3], negative pressure produced by a pump [4], adhesive materials [5], and a claw gripper [6]. Multiple actuators are always mounted on the drive unit of these robots. Additionally, these methods involve complicated mechanisms and require the adhered device to have a relatively large weight. In recent years, robots that apply drone technology have been developed. However, drone inspection technology has not advanced because it requires skill in investigations due to the effects of strong winds and thunderstorms.

The authors previously proposed an actuator capable of movement on a ferromagnetic material by coupling an electromagnetic force and a mechanical vibration [7 - 9]. Although this actuator can climb vertically, it cannot move over a stepped surface. Therefore, it cannot be used for the inspection of iron structures having a complicated shape. The proposed actuator system [10] is also capable of movement on the stepped surface, it cannot be equipped with a heavy sensor, such as an automatic tapping device.

This paper proposes a vibration actuator system that can move over an iron structure having a complicated surface with, for example, steps. First, the movement characteristics of the vibration actuator were examined. Next, a vibration actuator system prototype was built having four vibration actuators and magnetic wheels combined with flexible silicone rubber. Actual climbing tests showed that this actuator system can move smoothly over a stepped surface. This actuator system can be equipped with an automatic tapping device, and it has been shown that it may apply to inspection of large iron structures.

\section{STRUCTURE OF VIBRATION ACTUATOR}


Fig. 1 shows a diagram of the vibration actuator capable of movement on ferromagnetic material. The vibration actuator consists of a permanent magnet, a translational spring, an electromagnet, a triangular acrylic frame, a second permanent magnet attached to the bottom of the frame, and a natural rubber sheet. The upper permanent magnet, which made up the mass of the vibration component, was cylindrical and was composed of $\mathrm{NdFeB}$ magnetized in the axial direction. This magnet was $15 \mathrm{~mm}$ in diameter and $6 \mathrm{~mm}$ in height. The surface magnetic flux density measured using a tesla meter was $380 \mathrm{mT}$. The translational spring was a stainless-steel compression coil having an outer diameter of 14 $\mathrm{mm}$, a free length of $30 \mathrm{~mm}$, and a spring constant $\mathrm{k}$ of $4,812 \mathrm{~N} / \mathrm{m}$. The electromagnet consisted of an iron core having a diameter of $5 \mathrm{~mm}$ and a length of $25 \mathrm{~mm}$ with 1,000 turns of 0.2 -mm-diameter copper wire. This electromagnet was inserted into the translational spring.

The permanent magnet attached to the bottom of the frame had a diameter of $12 \mathrm{~mm}$ and a thickness of $5 \mathrm{~mm}$. The average surface magnetic flux density was $383 \mathrm{mT}$. A natural rubber sheet of $1 \mathrm{~mm}$ in thickness was attached to this permanent magnet to increase the frictional force. The vibration component was inclined at an angle $\alpha$ from the horizontal plane. The vibration actuator had a height of $42 \mathrm{~mm}$, a width of $15 \mathrm{~mm}$, and a total mass of $30 \mathrm{~g}$.

The angle $\alpha$ of the vibration component was set to $60^{\circ}$ based on the results obtained in a previous study [8]. The attractive force generated by the permanent magnet attached at the support part acts on the vibration actuator when it is placed on a ferromagnetic material, as shown in Figs. 2(a) and 2(b). The frictional force between the rubber sheet and the magnetic substance alternates periodically during one cycle of vibration. Because the horizontal component of the inertial force exceeds the frictional force, the vibration actuator

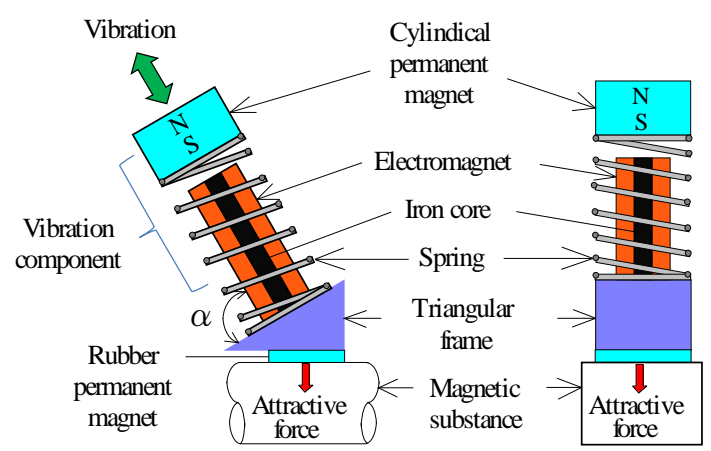

Fig. 1. Structure of the vibration actuator.

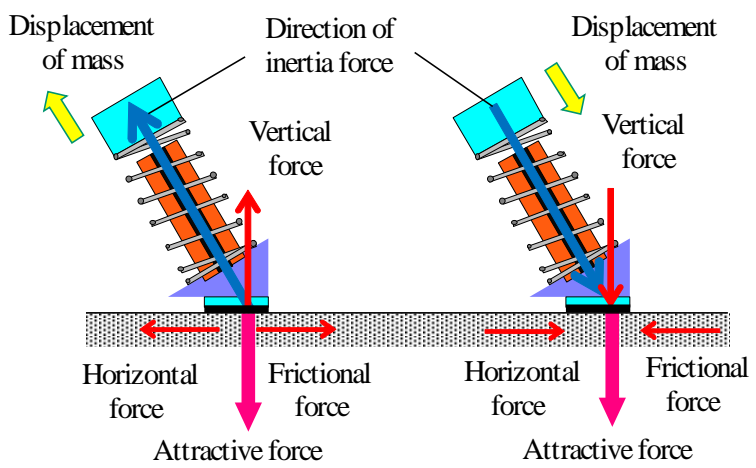

(Seconf permanent magnet)

(Seconf permanent magnet)

(a) Sliding

(b) No sliding

Fig. 2. Principle of locomotion.

is propelled by the difference between the frictional forces in the forward and backward directions acting on the rubber sheet, as shown in a previous study [8].

\section{LOCOMOTION CHARACTERISTICS OF VIBRATION ACTUATOR}

An experiment was conducted using the vibration actuator shown in Fig. 3. An iron rail with a width of $50 \mathrm{~mm}$, a thickness of $50 \mathrm{~m}$, and a length of $1,000 \mathrm{~mm}$ were used as the target magnetic structure. The vibration component was driven at a resonance frequency of $106 \mathrm{~Hz}$ using a signal generator and an amplifier. The attractive force $\mathrm{F}$ between the actuator unit and the iron rail was $8 \mathrm{~N}$. The coefficient of friction between the iron rail and the natural rubber as measured in the experiment was 0.67. Fig. 3 also shows a photograph of the vibration actuator.

Fig. 4 shows the relationship between the load mass and the vertical upward speed of the actuator when the input power was $0.6,0.9$, and $1.4 \mathrm{~W}$. In this figure, the actuator can move upward at a speed of $24.1 \mathrm{~mm} / \mathrm{s}$ even with a load mass of $650 \mathrm{~g}$.

Fig. 5 shows the relationship between the load mass and the self-propulsion efficiency of the actuator. The efficiency $\eta$ is expressed:

Vertical upward movement

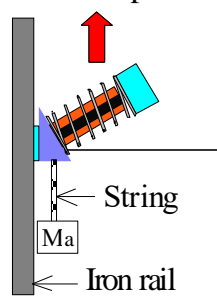

(a) Schematic

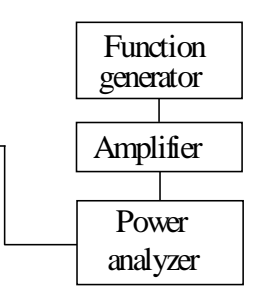

Fig. 3. Experimental apparatus and actuator. 


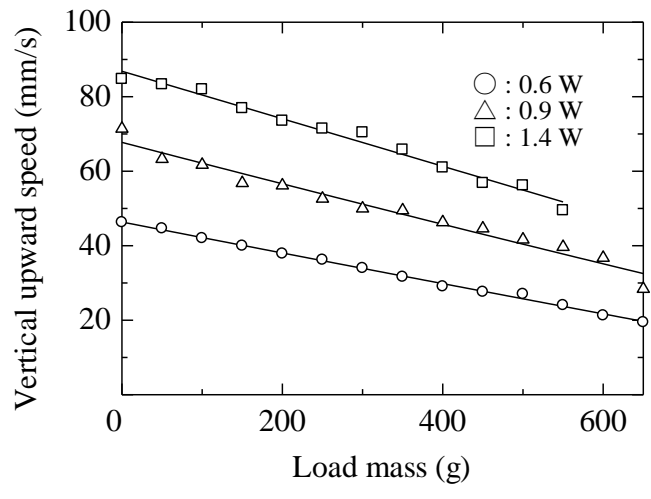

Fig. 4. Relationship between load mass and vertical upward speed for the single actuator.

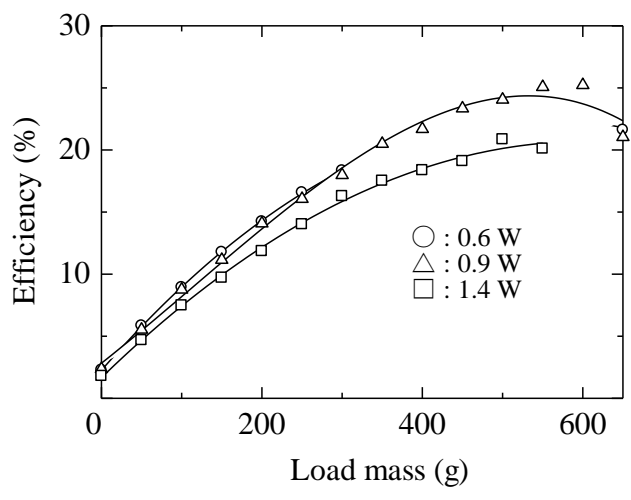

Fig. 5. Relationship between load mass and efficiency for the single actuator.

$$
\eta[\%]=\left(\mathrm{M}_{\mathrm{a}}+\mathrm{M}_{\mathrm{m}}\right) \mathrm{v}_{\text {up }} \mathrm{g} \times 100 / \mathrm{P}_{\mathrm{I}}
$$

where $M_{a}$ is the total mass of the actuator, $M_{m}$ is the load mass, $\mathrm{v}_{\text {up }}$ is the vertical upward speed, $\mathrm{g}$ is the acceleration due to gravity, and $\mathrm{P}_{\mathrm{I}}$ is the input power. It was observed that the maximum efficiency of this actuator is about $25.2 \%$.

\section{VIBRATION ACTUATOR SYSTEM CAPABLE OF MOVEMENT OVER A STEP}

To move on a complex iron structure having a stepped surface, the new vibration actuator system has a flexible frame capable of deformation over uneven parts of the structure surface. Silicone rubber was used for the flexible frame, and the attractive force was generated by multiple permanent magnets.

Fig. 6 shows a vibration actuator system in which four actuators (A, B, C, D) capable of movement are connected by a flexible silicone rubber frame. The silicone rubber is divided into five segments. The lengths of silicone rubber segments $\mathrm{A}, \mathrm{B}, \mathrm{C}, \mathrm{D}$, and $\mathrm{E}$ are $\mathrm{L}_{1}, \mathrm{~L}_{2}, \mathrm{~L}_{3}, \mathrm{~L}_{4}$, and $\mathrm{L}_{5}$, respectively. A magnetic wheel is attached to opposite ends of silicone rubber segments A and E. By attaching a magnetic wheel to the tip of the actuator system, it is possible to exert an appropriate attractive force on the iron structure and provide a guide for movement over a step. The magnetic wheel has a three-layer structure in which a ring-type permanent magnet is sandwiched between two acrylic disks having outer diameters of $30 \mathrm{~mm}$ and a thickness of $2 \mathrm{~mm}$. In addition, auxiliary permanent magnets are placed at distances $\mathrm{x}_{1}, \mathrm{x}_{2}, \mathrm{x}_{3}, \mathrm{x}_{4}$, and $\mathrm{x}_{5}$ from the origin $\mathrm{O}$ to adhere to an iron structure during movement over a stepped surface.

The longitudinal stiffness of the silicone rubber connecting the four actuators has a significant effect on the traction and movement over a step. Furthermore, the attractive force exerted by the magnetic wheel also affects the movement over the step. Because there are countless combinations of parameters for designing the actuator system, the following four criteria were introduced:

1) The total length of the actuator system is approximately $700 \mathrm{~mm}$ to allow portability.

2) Considering long cable traction over $200 \mathrm{~m}$, the traction force for the actuator system is more than $15 \mathrm{~N}$ (load mass of 1,500 g).

3 ) In the future, an automatic tapping device mass weighing $260 \mathrm{~g}$ can be installed in the center of the actuator system.

4) The height of the step-over which the actuator system can move does not exceed $25 \mathrm{~mm}$ in the vertical plane.

Preliminary experiments were conducted to satisfy the above design criteria. By trial and error, the dimensions of the silicone rubber material were determined. All silicone rubber segments A, B, C, $\mathrm{D}$, and $\mathrm{E}$ had a thickness of $5 \mathrm{~mm}$. In addition, the width $\mathrm{B}$ and length $\mathrm{L}$ of the silicone rubber were set to $B=20 \mathrm{~mm}$ and $\mathrm{L}_{1}=120 \mathrm{~mm}, \mathrm{~L}_{2}=140 \mathrm{~mm}$, $\mathrm{L}_{3}=140 \mathrm{~mm}, \mathrm{~L}_{4}=140 \mathrm{~mm}$, and $\mathrm{L}_{4}=120 \mathrm{~mm}$. As the auxiliary attractive force, cylindrical permanent magnets were arranged at $\mathrm{x}_{1}=0 \mathrm{~mm}, \mathrm{x}_{2}=165 \mathrm{~mm}$, $\mathrm{x}_{3}=305 \mathrm{~mm}, \mathrm{x}_{4}=-165 \mathrm{~mm}$ and $\mathrm{x}_{5}=-305 \mathrm{~mm}$ in segments A, B, C, D, and E. Cylindrical permanent magnets with an outer diameter of $15 \mathrm{~mm}$ and a thickness of $6 \mathrm{~mm}$ were attached at these positions. The attractive force on the iron rail for this magnet was $1.8 \mathrm{~N}$.

The ring-shaped permanent magnet for the magnetic wheels had an outer diameter of $16.5 \mathrm{~mm}$, an inner diameter of $8.5 \mathrm{~mm}$, a thickness of $4 \mathrm{~mm}$, and a magnetic flux density of $356 \mathrm{mT}$. A threelayered wheel with a shaft with an outer diameter 


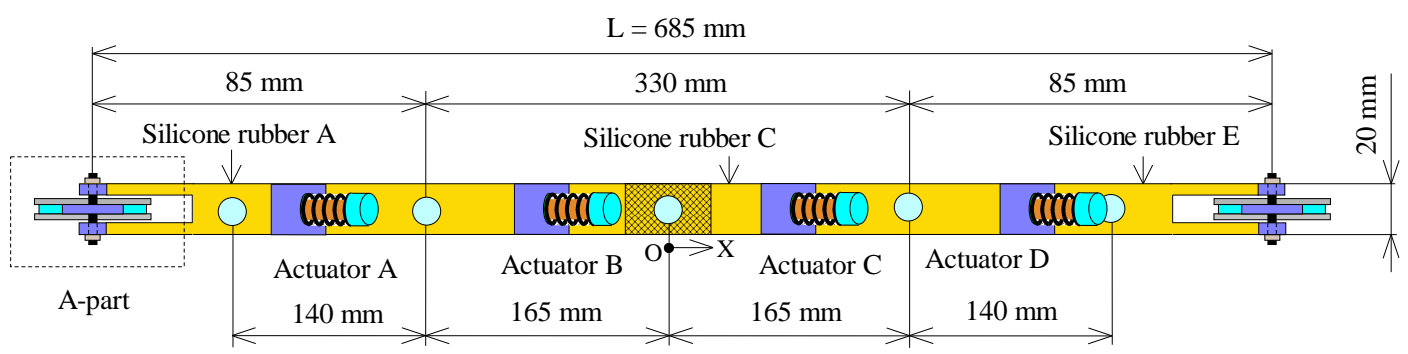

(a) Plan view

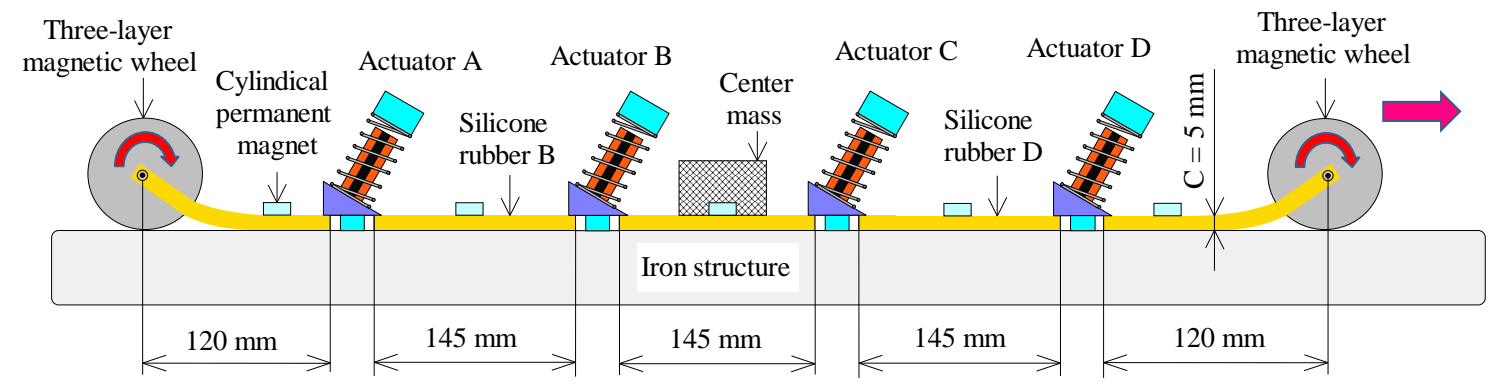

(b) Front view

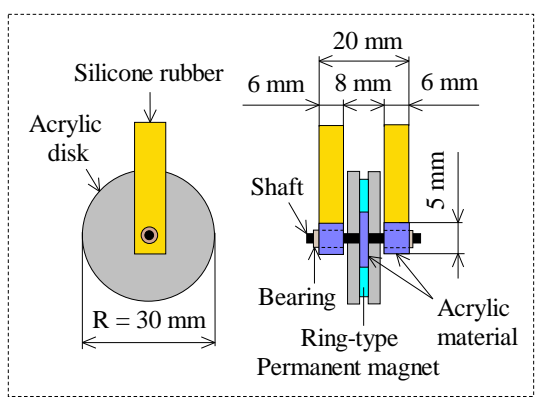

(c) Details of Area A in (a)

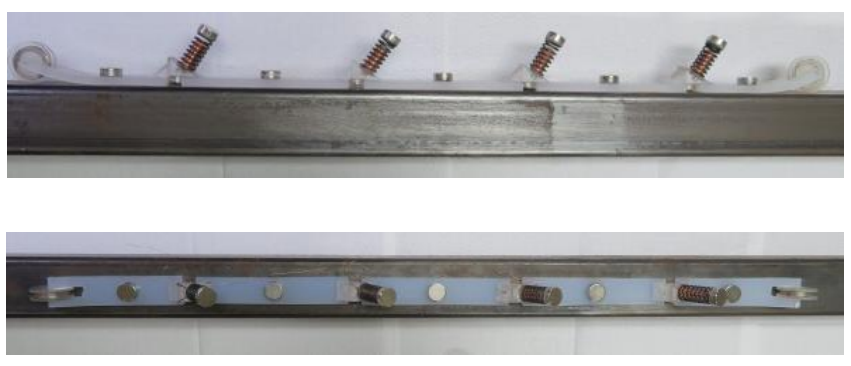

(d) Photograph of actuator system

Fig. 6. Vibration actuator system capable of movement over a step.

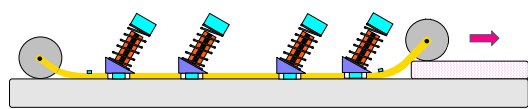

(a)

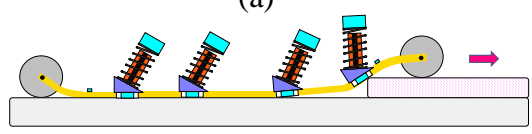

(b)

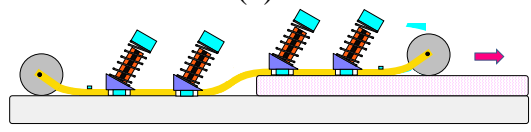

(c)

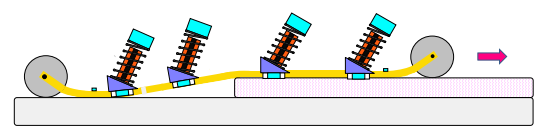

(d)

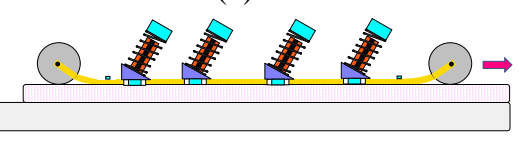

(e)

Fig. 7. Movement overstepped surface by vibration actuator system. of $1 \mathrm{~mm}$ in the center was attached to the silicone rubber via bearings. The attractive force for the magnetic wheel was $0.9 \mathrm{~N}$.

The overall length of the actuator system was $715 \mathrm{~mm}$, and the distance between the magnetic wheels was $\mathrm{L}=685 \mathrm{~mm}$. The width, height, and total mass of the actuator system were $20 \mathrm{~mm}, 42$ $\mathrm{mm}$, and $250 \mathrm{~g}$, respectively. In this system, the attractive force $\mathrm{F}$ for each vibration actuator was set to $8 \mathrm{~N}$. Fig. 6(d) shows photographs of the vibration actuator system.

Fig. 7 shows an image of the vibration actuator system moving over a step.

\section{LOCOMOTION CHARACTERISTICS OF VIBRATION ACTUATOR SYSTEM}

Measurements were performed using the experimental apparatus shown in Fig. 3. In the measurement, a square iron pipe with a width and height of $50 \mathrm{~mm}$, and a total length of 2,000 $\mathrm{mm}$ 
was used. The traction characteristics of the prototype actuator system were measured experimentally for the two load mass patterns shown in Figs. 8(a) and 8(b). For the load mass pattern in Fig. 8(a), Fig. 9 shows the relationship between the central mass (mock automatic tapping device) mounted in the actuator system and the

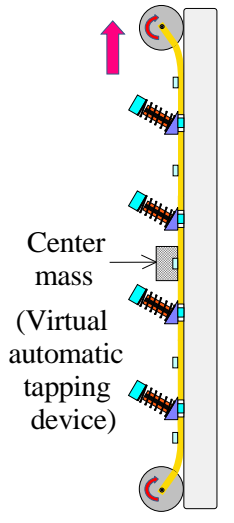

(a) Central mass

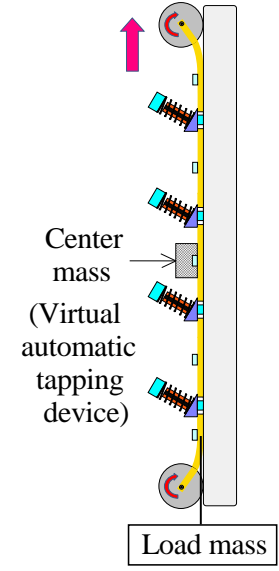

(b) Central and load masses Fig. 8. Two load mass patterns for climbing iron structures.

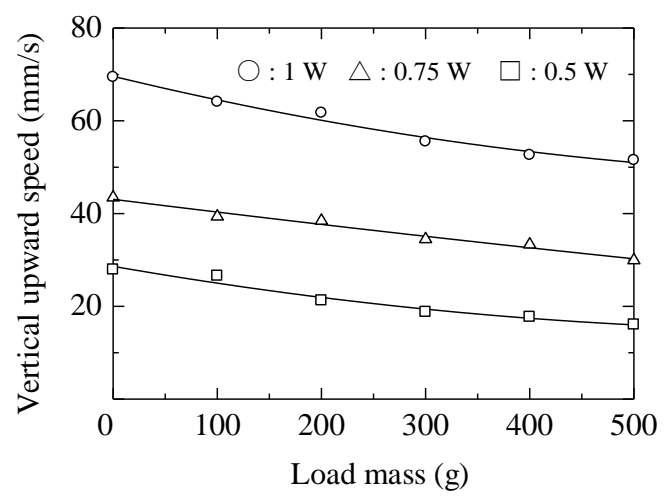

Fig. 9. Relationship between load mass and vertical upward speed with a central mass of $500 \mathrm{~g}$.

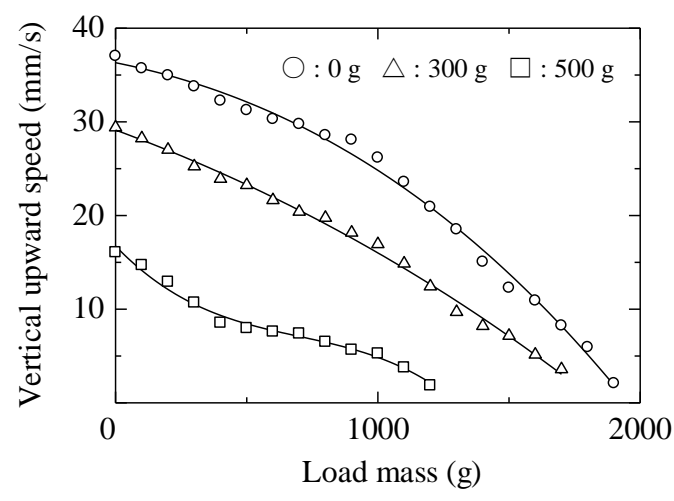

Fig. 10. Relationship between load mass and vertical upward speed with different central masses. vertical upward speed for different power inputs to one actuator. When $1 \mathrm{~W}$ is input to each actuator, it is possible to ascend vertically at a speed of 51.5 $\mathrm{mm} / \mathrm{s}$ while pulling a central mass of $500 \mathrm{~g}$.

For the load mass pattern in Fig 8(b), Fig. 10 shows the relationship between the load mass and the vertical upward speed for central masses of 0 , 300 , and $500 \mathrm{~g}$ with a $1 \mathrm{~W}$ input to each actuator. The load mass was attached to the silicone rubber with a string. When a central mass of $300 \mathrm{~g}$, which is heavier than a tapping device (260 g), was mounted on the actuator system, a vertical upward motion was possible at a speed of $7.2 \mathrm{~mm} / \mathrm{s}$ even when the maximum design load mass of $1,500 \mathrm{~g}$ was attached to the main body.

\section{STEP MOVEMENT CHARACTERISTICS OF VIBRATION ACTUATOR SYSTEM}

As shown in Fig 11, the locomotion characteristics of the vibration actuator system for two-step patterns were measured. First, as shown in Fig. 11(a), an iron structure having a single step with an infinite length was examined. In these experiments, the measurement distance was set to $750 \mathrm{~mm}$. The power input to each actuator was $1 \mathrm{~W}$.

Fig. 12 shows the relationship between the load mass of the actuator system and the vertical upward speed for a single step with a height of $25 \mathrm{~mm}$ by varying for central masses of $0,200,300,400$, and $500 \mathrm{~g}$. It was found that even with a central mass of $300 \mathrm{~g}$, a traction force of $5 \mathrm{~N}$ (load mass of $500 \mathrm{~g}$ ) was generated. However, the speed was only 6 $\mathrm{mm} / \mathrm{s}$. In the future, it will be necessary to take measures to increase the speed, such as changing the magnetic circuit in the vibration component.

Fig. 13 shows the relationship between the load mass of the system and the vertical downward speed for a single step with a height of $25 \mathrm{~mm}$ and central masses of 0, 200, and $300 \mathrm{~g}$. For downward movement, the results show that the speed increases as the load mass increases.

Furthermore, as shown in Fig. 11(b), the complex iron structure has two steps (defined as a single step of finite length, where the actuator system must crawl up the step where it begins and down the step where it ends) was examined. The power input to each actuator was $1 \mathrm{~W}$. In the experiment, the step height was fixed at $25 \mathrm{~mm}$, and the effect of the step length $L$ on the movement of the actuator system with no load mass was investigated. The step length $\mathrm{L}$ was varied from 50 to $550 \mathrm{~mm}$ at intervals of $50 \mathrm{~mm}$, 


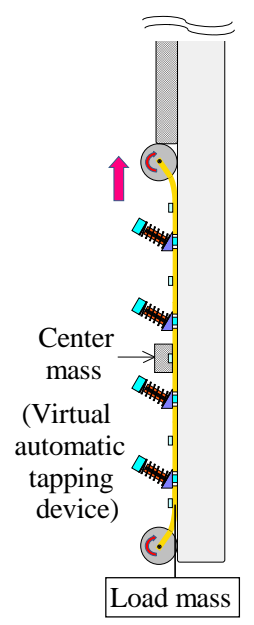

(a) Single infinite step

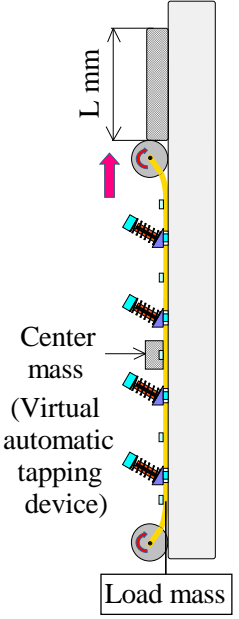

(b) Two steps

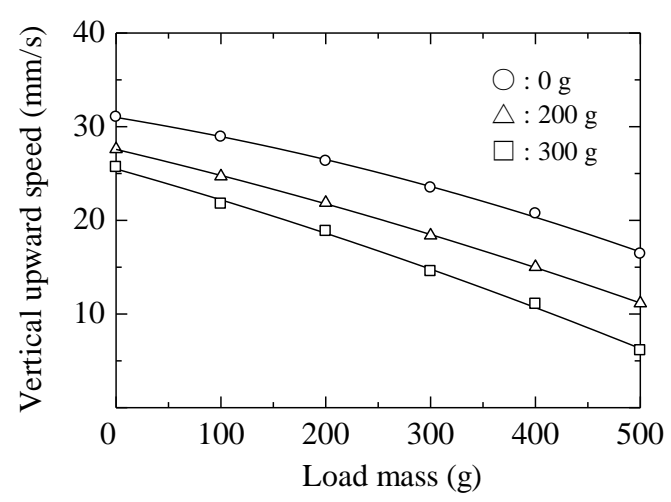

Fig. 12. Relationship between load mass and vertical upward speed for single infinite step.

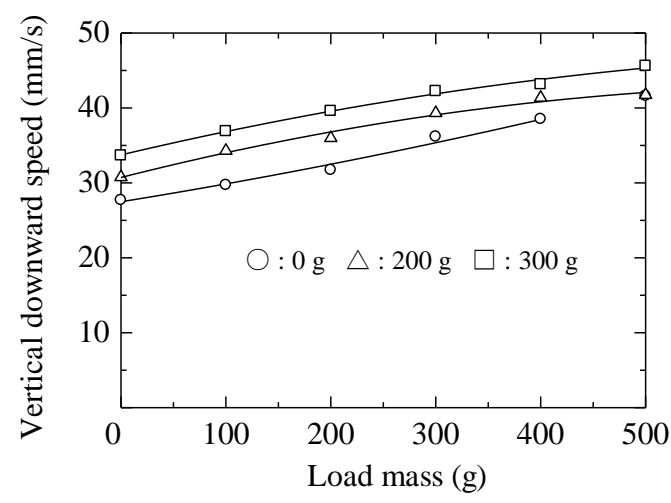

Fig. 13. Relationship between load mass and vertical downward speed for single infinite step.

and the vertical upward speed was measured. The step lengths over which the actuator system could move were 350,500 , and $550 \mathrm{~mm}$ or more. This is due to the placement interval of the vibration actuators in the system. An arrangement of vibration actuators that can handle any step length is an issue for the future.
The speed of the actuator system for the twostep case shown in Fig. 11(b) was measured. In these experiments, the step length was set to 500 $\mathrm{mm}$. The power input to each actuator was $1 \mathrm{~W}$.

Fig. 14 shows the relationship between the load mass and the vertical upward speed for a finitelength step $25 \mathrm{~mm}$ in height and central masses of 0,200 , and $300 \mathrm{~g}$. Even for a central mass of $300 \mathrm{~g}$, the system could move over the vertical surface while generating a traction force of $5 \mathrm{~N}$.

Fig. 15 shows the relationship between the load mass and the vertical downward velocity for a finite-length step $25 \mathrm{~mm}$ in height for central masses of 0,200 , and $300 \mathrm{~g}$. This actuator system proved capable of moving downward on a vertical surface with steps.

Compared to the infinite-length step (single step), the speed in the case of a finite-length step (two steps) was considerably reduced. This is because three actuators required large propulsive forces to overcome the attractive force between the permanent magnet in the holding part of one actuator and the stepped part of the iron structure. In the future, it will be necessary to improve the

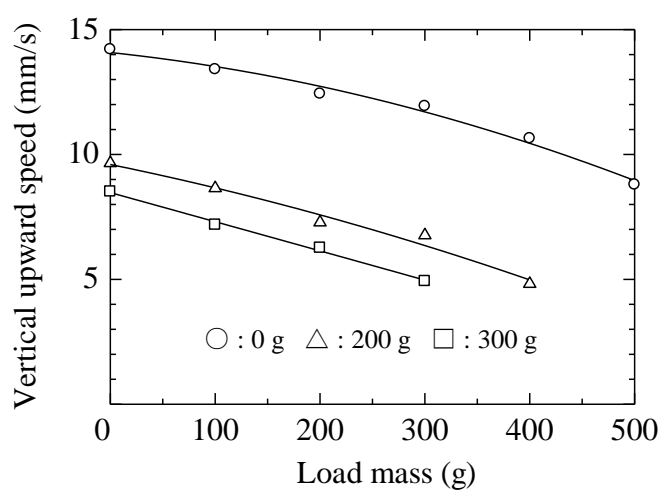

Fig. 14. Relationship between load mass and vertical upward speed for finite double step.

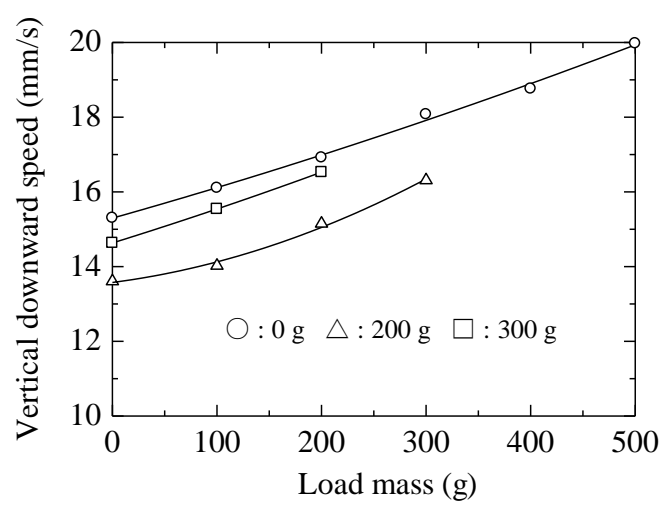

Fig. 15. Relationship between load mass and vertical downward speed for finite double step. 
holding part using a design that combines a permanent magnet and an electromagnet. This will allow control of the attractive force according to the movement conditions.

In addition, this actuator system cannot switch the movement direction. To solve this problem, it is necessary to change the actuator to a structure that uses a vibration phase difference, as previously proposed by the author [9].

\section{CONCLUSION}

The demand for inspection of structures is increasing all over the world. However, it is very difficult to move on a complex iron structure having a step on a vertical surface. In this paper, a new vibration actuator system for the inspection of complex iron structures has been proposed.

At first, a single vibration actuator was prototyped and measured. The experimental results revealed that this vibration actuator was able to move with a load mass of $650 \mathrm{~g}$. It is a maximum efficiency of about $25.2 \%$ for the case of carrying only its weight.

Next, to move on a complex iron structure having a stepped surface, the vibration actuator system was prototyped with four vibration actuators and magnetic wheels combined with a flexible silicone rubber frame. The actuator system produced a traction force of $19 \mathrm{~N}$. In addition, even for a load mass of $300 \mathrm{~g}$, the approximate weight of an automatic tapping device, the system could move vertically over a step $25 \mathrm{~mm}$ tall. Thus, this actuator system can move on a complex iron structure which is difficult even for a robot equipped with a complicated control system. However, this actuator system cannot switch its direction of movement. To solve this problem, it is necessary to change the actuator to a structure that uses a vibration phase difference, as previously proposed by the author [9].

\section{REFERENCES}

[1] Kanada A., Giardina F., HowisonT.,Mashimo T. and Iida F., "Reachability Improvement of a Climbing Robot based on Large Deformations induced by Tri-Tube Soft Actuators, Soft Robotics Vol. 6, No. 4 (2019).

[2] Ge D., Ren C., Ma S., and Matsuno T., Guide Rail Design for a Passive Suction Cup-based
Wall-Climbing Robot, in Proc. 2016 IEEE/RSJ International Conference on Intelligent Robots and Systems (IROS2016), pp. 5776-5781 (2016).

[3] Kim S., M. Spenko, S. Trujillo, B. Heyneman, V. Mattoli and M. R. Cutkosky, "Whole-body adhesion hierarchical directional and distributed control of adhesive forces for a climbing robot", IEEE International Conference on Robotics and Automation, pp. 1267-11273 (2007).

[4] Subramanyam A., Mallikarjuna Y., Suneel S.and Bhargava K. L., " Design and Development of a Climbing Robot for Several Applications", International Journal of Advanced Computer Technology, Vol. 3, No. 3, pp. 15-23 (2011).

[5] Unver O. and Sitti M., " Tankbot: A Miniature, Peeling Based Climber on Rough and Smooth Surfaces", in Proc., IEEE International Conference on Robotics and Automation, pp. 2282-2287 (2009).

[6] Provancher W., Ensen-Segal S. and Fehlberg M., " ROCR: An Energy-Efficient Dynamic Wall-Climbing Robot", IEEE Transaction on Mechatronics, Vol. 16, No. 5, pp. 897-906 (2011).

[7] Yaguchi H. and Sakuma S., " Characteristic Improvement of a Magnetic Actuator Capable of Movement on a Magnetic Substance", IEEE Trans. Magn., Vol. 52, No. 7, Article\#: 10.1109/TMAG.2016.2533433 (2016).

[8] Yaguchi H., and Sakuma S., Vibration Actuator Capable of Movement on Magnetic Substance Based on New Motion Principle, Journal of Vibroengineering, Vol. 19, Issue 3, pp. 1494 - 1508 (2017).

[9] Yaguchi H., A new type of electromagnetically propelled vibration actuator for appearance inspection of the iron structure, International Journal of GEOMATE, Vol. 20, No. 77, pp. 69 - 76 (2021).

[10] Yaguchi H., and Itoh Y., the Vibration actuator A system with a small-scale size capable of visual inspection of large complex iron structures, Applied Sciences, Vol. 11, No. 16 , pp. 1 - 16 (2021).

Copyright (C) Int. J. of GEOMATE. All rights reserved, including the making of copies unless permission is obtained from the copyright proprietors. 